Páipéar Taighde Teicniúil

Research Technical Paper

Sovereign Bond-Backed Securities:

A VAR-for-VaR and Marginal Expected Shortfall Assessment

Maite De Sola Perea, Peter G. Dunne, Martin Puhl \& Thomas Reininger 


\title{
Sovereign Bond-Backed Securities: A VAR-for-VaR and Marginal Expected Shortfall Assessment
}

\author{
Maite De Sola Perea \\ Peter G. Dunne* \\ Martin Puhl \\ Thomas Reininger
}

February 2018

\begin{abstract}
Brunnermeier et al., (2017) propose a securitisation solution for the bank-sovereign doom-loop. This shields senior tranche investors from actual defaults but whether it stabilises flight-to-safety panics is unclear. We apply dynamic VaR and Marginal Expected Shortfall methods to assess whether real-time risks to investors are attenuated by holding sovereign bond-backed securities. Price dynamics are derived using a Monte Carlo method. We find that holders of the senior tranche would be as safe as holders of German bunds. Mezzanine risk exposure would be moderate. The junior tranche experiences less severe shocks than high-risk sovereigns. The proposal significantly reduces destabilising market dynamics.
\end{abstract}

JEL classification: E43, E44, E52, E53, G12, G14.

Keywords: Safe Assets; Sovereign Bonds; Value-at-Risk; Spillover; CAViaR; Co-Dependence.

\footnotetext{
*Central Bank of Ireland, E-mail: peter.dunne@centralbank.ie. Address: New Wapping Street, Dublin 1, Ireland. Maite De Sola Perea, National Bank of Belgium. Martin Puhl and Thomas Reininger, Oesterreichishe Nationalbank. Views expressed are those of the authors and not necessarily the official views of the Banks. We are grateful to Sam Langfield, Marco Pagano, Richard Portes, Philip Lane, Javier Suárez, Kitty Moloney, Patrick Haran, Angelo Ranaldo and members of the ESRB High-Level Task Force on Safe Assets for helpful comments. This work also benefited from comments following presentation at the Annual Irish Economic Association Conference, 2017.
} 


\section{Non-Technical Summary}

Brunnermeier et al., (2017) proposed a sovereign bond-backed securitisation solution to the problem of euro area banks' concentrated exposures to their own country's sovereign bonds. This paper forms part of the research-based evidence of the ESRB Task Force on Safe Assets that was set up to assess the proposal. The securitisation creates a tiered structure of subordination such that, holders of the most junior claims are hit with the first default losses. This forms a buffer that protects holders of the more senior tranches of the securitisation.

It is claimed that such a securitisation would automatically spread the exposure of banks across the underlying sovereigns and improve the quality of their financial assets. Banks have tended to concentrate their holdings in the bonds of their home sovereign and, during the crisis, sovereigns chose to recapitalise their failing banks. Sovereign risk and bank solvency became intertwined in a damaging doom-loop. If banks mainly hold the senior tranche of a sovereign bond-backed securitisation they should be substantially protected from default losses of their own, and other, sovereigns. In addition, a successful sovereign bond-backed securitisation could substantially increase the supply of safe assets and reduce negative spillovers of volatility between sovereign markets.

Although there has been a lot of work confirming how sovereign securitisation would reduce exposure to simulated defaults, there is limited consideration of how variation in expectations of default interacts with bond markets in real-time. These interactions are important because fear itself (as well as ambiguity about policy responses) can drive markets and this can push yields to levels that make debt roll-over too expensive to be sustainable. So even if default is not warranted based on fundamentals, a sovereign may still lose market access and may have to default due to illiquidity rather than insolvency.

To assess real time market risks and their interactions we apply dynamic VaR and Marginal Expected Shortfall methods. Price dynamics are derived using the Monte Carlo method of Schönbucher (2003). We find that senior tranche investors would be as safe as holders of German bunds and both can be regarded as safe havens. Mezzanine risk exposure would be moderate. Investors in the junior tranche experience much less severe shocks than investors holding high-risk sovereigns. This is mainly due to a diversification effect. Risk taking is also well rewarded when holding sovereign bond-backed securities. Overall, the proposal significantly reduces destabilising (potentially self-fulfilling) market dynamics. 


\section{Introduction}

This paper examines tail risk exposure and hedging properties of estimated yields on sovereign bond-backed securities (SBBS) proposed by Brunnermeier et al (2011, 2016, 2017). The proposed securitisation involves the replacement of a proportion of the supplies of individual European sovereign bonds with senior, mezzanine and junior tranches backed by the purchased sovereigns. The junior and mezzanine components would, in turn, be exposed to agreed levels of losses from defaults on the underlying securities (e.g. 10\% and $20 \%$ respectively) before senior bond holders would become liable. Simulations by Brunnermeier and others have shown that senior bonds in this securitisation are ex post fundamentally of lower risk than any existing individual sovereign while the mezzanine and junior tranches should experience expected loss rates comparable to those of euro area sovereigns with intermediate and higher credit risks respectively.

However, the existing risk assessments are based on simulated default outcomes - based on a variety of assumed probabilities of defaults, default correlations and expected losses given defaults - rather than on the losses that arise from fluctuations in the market valuation of the securities. This leaves a gap in our understanding of the effects of 'flights-to-safety' and any other type of market panic that could arise from perceptions and doubts about risk exposures of SBBS in very extreme circumstances (and the real feedback effects that these produce). There remains a concern that, when expected losses on mezzanine or junior bonds are at very high levels, the senior SBBS may suffer much larger mark-to-market valuation risks than existing safe assets. Another concern is that there may be insufficient interest in holding the junior bond given that its yield (when compared with single risky sovereigns) may be too low to compensate for its high level of embedded leverage. Lastly, it is of interest to compare the risk attributes of the proposed securities with those of a diversified portfolio of sovereign bonds to assess the ex ante benefits that arise from tranching beyond pure diversification effects. These issues can be addressed if realistic estimates of SBBS yields can be derived.

We implement a pricing tool using historical market data, and a correlated multivariate Monte Carlo approach based on a static copula as described in Schönbucher (2003), to derive probable yields on the SBBS components of a variety of securitisation structures 
over roughly a 17-year history 11 The present analysis uses the estimated yields to ascertain whether the securitisation structure subdues shocks in a way that stabilises markets. They also permit an assessment of whether SBBS are relatively more attractive to investors when compared with individual sovereigns or a weighted pool of euro area sovereigns.

The VAR-for-VaR and MES are ex ante measures of outcomes under extreme market circumstances. The VAR-for-VaR reveals how the likelihood of extreme outcomes in one asset relates to another given some causal ordering (see, Engle and Manganelli, 2004 and White, Kim and Manganelli, 2015). The MES, in contrast, reveals how one asset is expected to fare in terms of expected return when another asset is likely to be experiencing a tail event (we follow the MES procedure outlined in Brownlees and Engle, 2012 where MES contributes to their SRISK measure). MES can therefore capture flight-to-safety dynamics (i.e. a positive outcome when a riskier asset is expected to be experiencing an extremely negative outcome). This can easily be generalised to consider the expected shortfall in one asset based on the probability of a tail event in another single asset (or SBBS) ${ }^{2}$

Flights-to-safety will have historically depressed the lowest-risk sovereign yields by more than would be likely if there was a much larger supply of low-risk assets (i.e. if senior SBBS existed and became a substitute for safe heavens). Estimations based on simulations from this history will tend to depress yields too much on the senior SBBS. To address this issue we adjust the Monte Carlo fitting process by imposing a high correlation in the triggering of defaults (all pairwise correlations in the default triggering mechanism are set to +0.6 ). The high correlation in the default triggering mechanism increases the incidents in which simulated losses overwhelm the junior tranche (and occasionally the mezzanine too). Under this calibration the estimated senior SBBS yield will be attributed some of the historical premium to compensate for the small amount of simulated losses.

There remain, of course, some limitations on how well the past can be made an adequate representation of a counter-factual institutional arrangement. Brunnermeier et al (2017) model the bank-sovereign diabolic loop, and find that it would be significantly weakened insofar as banks replace their current sovereign bond holdings with senior SBBS. So our

\footnotetext{
${ }^{1}$ This Monte Carlo estimation method is explored in more detail in the report of the ESRB High-Level Task Force on Safe Assets (2018).

${ }^{2}$ Other related risk measures that are not as suitable for our purposes include Systemic Expected Shortfall (SES) by Acharya et al. (2010) and $\Delta$ Co-VaR as proposed by Adrian and Brunnermeier (2011).
} 
analysis, being based on a history without this positive externality, will tend to overstate risks and their spillovers.

Notwithstanding this Lucas-type critique, the VaR and MES risk metrics can provide indications of the level of contagion between different tranches of SBBS in their exposures to extreme risks. The "VAR-for-VaR" applied to the bivariate relations between senior, mezzanine and junior bonds can highlight how valuation-based risks fluctuate in the senior bond when such risks fluctuate in the mezzanine or junior tranches. The MES analysis applied to the senior/mezzanine pairing of assets (where the mezzanine security has elevated $\mathrm{VaR}$ and is the causal asset) can reveal how increased downside risk in the mezzanine translates into expected return on the senior tranche. This gives insights about the hedging and diversification benefits of the senior bond that facilitates comparison with individual sovereign bonds and a diversified portfolio.

We extend our analysis to ascertain whether investors are adequately rewarded for the actual and expected risks of their holdings. A commonly used measure is the Sharpe ratio (Sharpe 1966, 1994) which, in an ex post sense, is the average excess holding period return relative to historical standard deviation of such returns. However, it is also valid to examine expectations of excess returns relative to conditional expected standard deviation of returns. We use GARCH-implied conditional standard deviation and projections of holding period excess returns to derive dynamic Sharpe ratios. In addition to our analysis of the adequacy of holding period excess returns as a return for risk, we also examine yield-to-maturity relative to conditional volatility (and relative to absolute Value-at-Risk) of yield-to-maturity movements. All reward-for-risk measures are compared across SBBS tranches, a euro area GDP-weighted portfolio of sovereign bonds and individual sovereigns.

Our findings imply that the senior SBBS has low levels of tail risk exposure (as low as, and often lower than, the tail risks of the lowest-risk euro area sovereign). Senior bonds also retain similar hedging properties to the lowest-risk sovereign - protecting against exposure to the spillover of losses from tail events in the mezzanine and junior bonds (this remains the case even when there is a two-tier tranching structure). The mezzanine tranche ranks as similarly exposed to tail risk as Italian and Spanish bonds. However, junior assets are very similar in terms of tail risk exposure to Irish and Portuguese bonds and they are less exposed to tail risks than Greek bonds. 
The note is arranged as follows. In the next section we briefly outline the data and methodologies employed. In section 3 we discuss the results from application of the VARfor-VaR and MES applications. This is followed by concluding comments.

\section{Data \& Methodology}

\subsection{Data}

The following senior:mezzanine:junior tranching proportions were used in the VAR-for-VaR and MES analysis; 70:30, 80:20, 90:10, 70:20:10, 80:10:10. We only discuss a subset of the results (i.e those for 70:20:10 and 70:30 tranching structures) ${ }^{3}$ The VAR-for-VaR and MES for the estimated yields is compared with that of individual bonds of 11 euro area countries and with a euro area GDP-weighted portfolio. The results presented apply to assets with 10 years to maturity. Our sample runs from the beginning of January 2003 to the end of October 2016. Daily data for individual sovereign bond yields were sourced from Datastream. Yields for the securities backed by these sovereign bonds were estimated using the methodology discussed below and these were then treated in the same way as other individual sovereign bonds in the VAR-for-VaR and MES analysis. The negative of the daily yield change in basis points is used as the model variable $4^{4}$

\section{$2.2 \quad$ Estimating SBBS Yields}

We estimate the yields of SBBS tranches with a multivariate Monte Carlo simulation that is based on a static copula approach as described e.g. in Schönbucher (2003). We create a joint distribution function of country-specific random variables to derive scenarios in which the individual country may default. The joint distribution function is created with a Gaussian copula and thereby transformed into country-specific uniform variables between 0 and 1 that are correlated. Depending on the actual historical default probability (PD) of the respective country, a country defaults if the value of its random variable (i.e. one scenario within the simulation run per day and country) exceeds the threshold of (1-PD). For

\footnotetext{
${ }^{3}$ Results for other cases, including other maturity categories and other default correlations, are available from the authors.

${ }^{4} \mathrm{~A}$ related analysis of the price returns is available from the authors but this produces very similar results. In this case the bond price is approximated as (100 - 10 (yield - coupon)).
} 
example random values above 0.96 lead to a default for a country with a PD of $4 \%$. In this way, the scenarios define which country bonds in the SBBS structure defaults and allows the calculation of the associated loss. The losses are assigned to the different tranches according to the predefined tranching structure and allows the construction of tranchespecific expected loss (EL) distributions. The overall risk premium (yield exceeding the risk free rate) of the bond portfolio is then allocated to the tranches according to their EL. Consistency checks ensure that the weighted average yield of the tranches is identical to the yield of the underlying bond portfolio.

The estimation is largely based on historical market data. For the default probabilities and LGD values of the individual countries, we use the bond-implied PD values of the respective day. The implied $\mathrm{PD}$ is estimated as the bond yield minus the risk free rate 5 Datastream benchmark government indices are used for the yield time series of the respective governments. Furthermore, for simplicity we use the lowest country bond yield as the risk-free rate of the respective day. For the country correlation in the default scenario generator, we set a constant value of $60 \%$. This means that the random variables determining default events are noticeably interdependent.6 30,000 scenarios per day and country have been used for the simulation. For the generation of (uniform) correlated default scenarios, we used the R package MASS. The simulation is based on yield data for 2, 5 and 10 year government bonds of Austria, Belgium, Germany, Spain, Finland, France, Greece, Ireland, Italy, the Netherlands and Portugal. Following a weighting scheme based on GDP (average between 2006-2015), those countries cover $97.5 \%$ of the volume of the SBBS.

\subsection{VAR-for-VaR}

The VAR-for-VaR methodology of White et al (2015) is essentially a vector autoregression applied to quantile relations in which autoregressive cross-effects are permitted. This

\footnotetext{
${ }^{5}$ Assuming an LGD of $100 \%$. For the used correlation assumptions of $60 \%$, the yield is no longer fully independent of the subdivision of EL into PD and LGD. For LGD values above $60 \%$ the yields start to diverge slightly. For instance, on the basis of a 70/30 tranching structure and a default correlation assumption of $60 \%$, the junior bond yield for LGD values of $30 \%, 60 \%$ and $100 \%$ are $2.63 \%, 2.61 \%$ and $2.52 \%$, respectively, as of $31 / 10 / 2016$, while the seior bond yields are $0.08 \%, 0.09 \%$ and $0.13 \%$. In order not to understate the yield and resulting expected loss of the senior bond (in comparison to the German bund) and not to overstate the attractiveness of junior bonds, we decided to use an LGD of $100 \%$.

${ }^{6}$ Note that the different PDs of the respective countries also influences the occurrence of default events. Even in the case of $100 \%$ correlation, the random variable would have to surpass a different PD threshold for e.g. Germany than for Portugal.
} 
extends the Conditional Autoregressive Value at Risk (CAViaR) model of Engle and Manganelli (2004) to a multivariate context. Cross-effects can be between different lagged quantile levels of the same asset but of more interest are the cross-effects arising from quantiles of returns on other assets. In the case of a relation between the lowest-risk asset and higher-risk assets the VaR cross-effects will often be negative (i.e., the lowest-risk asset will have VaR that is becoming less negative while the VaR of the higher-risk assets is becoming more negative).

The VAR-for-VaR approach fits a parameterised smoothed step-function of predetermined variables to choose a quantile value and a categorisation of returns that produces the appropriate number of exceedences of the quantile using an optimisation strategy based on Koenker and Bassett (1978). For a pair of asset returns, $y_{m t}, y_{a t}$, and associated quantiles, $q_{m t}, q_{a t}$, the period 't' quantiles are related to the most recently estimated quantiles in 't-1' and lagged returns as follows;

$$
\begin{aligned}
& q_{m t}=c_{1}+a_{11} y_{m t-1}+a_{12} y_{a t-1}+b_{11} q_{m t-1}+b_{12} q_{a t-1} \\
& q_{a t}=c_{2}+a_{21} y_{m t-1}+a_{22} y_{a t-1}+b_{21} q_{m t-1}+b_{22} q_{a t-1}
\end{aligned}
$$

Although different quantile levels can be jointly modeled, we estimate the case where a common quantile (e.g. 1\%) is chosen for each distribution.

\subsection{Marginal Expected Shortfall}

Marginal Expected Shortfall is the expected return on a specific asset where the expectation takes account of (i) the joint distribution of the standardised returns of the specific asset and a causal asset (e.g. the market) and (ii) the probability of a tail event in the causal asset. The correlation between returns in the joint density of the observations therefore plays a vital role in determining the marginal expected shortfall. For example, when one asset is a safe haven and the other a high-risk asset, it is possible that the marginal expected shortfall of the low-risk asset would be a highly positive outcome when the high-risk asset is experiencing a tail event. In this case, returns on the low-risk asset (conditional on a tail event in the high-risk asset) may exceed average returns on the low-risk asset (so the 'shortfall' terminology can be misleading).

More formally, let the expected value of the standardised market return in the tail be 
$E_{t-1}\left(\epsilon_{m t} \mid \epsilon_{m t}<C / \sigma_{m t}\right)$ and the conditional expected specific-return be denoted $E_{t-1}\left(\xi_{i t} \mid \epsilon_{m t}<\right.$ $\left.C / \sigma_{m t}\right)$ where $\mathrm{C}$ is set to the market non-parametric $1 \%$ VaR. MES is then measured as;

$$
\begin{aligned}
M E S_{i t-1}(C) & =E_{t-1}\left(r_{i t} \mid r_{m t}<C\right) \\
& =\sigma_{i t} E_{t-1}\left(\rho_{i t} \epsilon_{m t}+\sqrt{1-\rho_{i t}^{2}} \xi_{i t} \mid \epsilon_{m t}<C / \sigma_{m t}\right) \\
& =\sigma_{i t} \rho_{i t} E_{t-1}\left(\epsilon_{m t} \mid \epsilon_{m t}<C / \sigma_{m t}\right)+ \\
& \sigma_{i t} \sqrt{1-\rho_{i t}^{2}} E_{t-1}\left(\xi_{i t} \mid \epsilon_{m t}<C / \sigma_{m t}\right) .
\end{aligned}
$$

Following Scaillet(2005) we measure the conditional tail expectations as:

$$
E_{t-1}\left(\epsilon_{m t} \mid \epsilon_{m t}<C / \sigma_{m t}\right)=\frac{\sum_{t=1}^{T} \epsilon_{m t} \Phi\left(\frac{c-\epsilon_{m t}}{h}\right)}{\sum_{t=1}^{T} \Phi\left(\frac{c-\epsilon_{m t}}{h}\right)} ; \quad E_{t-1}\left(\xi_{i t} \mid \epsilon_{m t}<C / \sigma_{m t}\right)=\frac{\sum_{t=1}^{T} \xi_{i t} \Phi\left(\frac{c-\epsilon_{m t}}{h}\right)}{\sum_{t=1}^{T} \Phi\left(\frac{c-\epsilon_{m t}}{h}\right)} .
$$

where $\Phi$ denotes the cumulative normal density and Silverman's "rule of thumb" method is used to determine the bandwidth $h$ (see, Silverman (1986)).

Practically, the estimation of MES also requires conditional volatility and correlation. These are estimated using an asymmetric DCC-GJR-GARCH process (see, Glosten et al (1993)). This specification allows for both a leptokurtic distribution in the returns and common volatility characteristics such as volatility clustering. The asymmetry captures a leverage effect commonly observed in asset markets where negative returns increase volatility more than positive returns. As discussed by Engle $(2002,2009)$ an important feature of this specification is that the autoregressive parameters are restricted so that the expected long-run correlation is equal to unconditional correlation.

\subsection{Measuring Reward-for-Risk}

To ascertain whether investors are adequately rewarded for the expected risks in their holdings we calculate Sharpe ratios for SBBS tranches, a euro area GDP-weighted portfolio of sovereign bonds and individual sovereigns. In the case of bond investments, the calculation of the excess return component of the Sharpe ratio involves adding capital gains (or losses) to accrued coupons and subtracting a risk free rate. The coupon can sometimes be an important component of holding period returns 7 The standard deviation of the holding period return (i.e. standard deviation of the bond price changes) can be approximated as

\footnotetext{
${ }^{7}$ Unfortunately, we do not have an obvious way to determine what coupon would apply to the senior, mezzanine and junior tranches of SBBS. We address this by assessing the Sharpe calculations for a range of coupon assumptions based on the historical relation between coupons and yield spreads across issuers.
} 
duration times the standard deviation of yield changes.

In our analysis the monthly holding period return is calculated as follows (where the euribor is the 1 month swap of fixed for floating interbank rate recorded at the beginning of period t);

$$
r_{t}=\frac{\Delta P_{t}}{P_{t-1}}+(\text { coupon }(i)-\text { euribor })_{t} / 12
$$

We calculate the price change using an approximation based on yield changes suggested by Shirvani and Wilbratte (2005) as follows (where D is the duration);

$$
\frac{\Delta P_{t}}{P_{t-1}} \approx\left(1+\Delta y_{t} /\left(1+y_{t-1}\right)\right)^{-D}-1
$$

This is also the basis for the conversion of yield volatility to price volatility as follows;

$$
\operatorname{StDev}\left(\frac{\Delta P_{t}}{P_{t-1}}\right) \approx\left(1+\operatorname{StDev}\left(\Delta y_{t}\right) /\left(1+y_{t-1}\right)\right)^{-D}-1
$$

We approximate a high and low coupon based on the fitted relation between yield spreads and coupon spreads (where the yield spread is the spread relative to the bond with the lowest yield and the coupon spread is the spread relative to the risk free return). Using euro area sovereign bond coupon data from Bloomberg, we find that the approximate relation between the coupon spread and yield spread from January 2012 to end-October 2016 is as follows (standard errors of coefficient estimates are shown below the coefficient estimates) 8

$$
\begin{aligned}
& (\operatorname{coupon}(i)-\text { euribor })_{t}=3.08+0.42(\text { yield }(i)-\min (\text { yield }))_{t} \\
& \text { (0.35) (0.21) } \\
& \operatorname{Adj} \bar{R}^{2}=0.23
\end{aligned}
$$

We use a two standard deviation shift of the intercept (in both directions) to derive lower and upper bounds for the coupon assumption for each yield and we restrict the coupon to a maximum of $10.5 \%$. We also round the coupon to the nearest whole percentage and this leads to a variable that mimics more closely what we observe in the individual sovereign historical coupon series. In all related calculations we make sure that the duration is

\footnotetext{
${ }^{8}$ We excluded Greek bonds from this exercise due to the excessively large yield spread during the crisis since this dominates the regression when included.
} 
appropriately adjusted for the different levels of the coupons. The fitted coupon rises with yield. This may bias our results towards the finding of a higher Sharpe ratio for the relatively higher-risk sovereigns (and for the higher-risk SBBS). To counter this bias we also consider a case where we imposed a static equal coupon across all the bonds/portfolios/SBBS in our analysis. This reveals a remarkably similar pattern and relative position for the Sharpe ratios.

A dynamic Sharpe ratio can be constructed using a moving average of monthly returns divided by GARCH-implied conditional standard deviation and this is the approach taken here. In addition to the analysis of excess holding period returns we also assess yield-tomaturity relative to conditional volatility of yield-to-maturity movements and relative to Value-at-Risk. These can be considered as analogous to Sharpe ratios in the sense that we consider a reward relative to a standard risk metric. Yield and price volatility are directly related to each other but, since yield-to-maturity and the holding period return are not necessarily related it is possible that a Sharpe ratio based on yield-to-maturity offers a perspective of interest to longer term investors. We therefore propose a quasiSharpe ratio for this measure of reward (i.e. yield-to-maturity relative to standard deviation of changes in yield-to-maturity). This may give different reward-for-risk rankings of the bonds/portfolios/SBBS to those based on the Sharpe for the holding period return because the latter are sensitive to the size of the coupon. Since we also measure risk using conditional VaR (based on extreme yield rises) we are led to employ a third Sharpe-like measure of reward for risk exposure (i.e. simply the yield-to-maturity relative to VaR). This can be thought of as measuring the return that holders-to-maturity obtain for exposure to different levels of default-risk (since default risk and extreme yield rises are likely to be highly correlated).

\section{Results}

\subsection{Comparing Measured Risks}

We present the majority of our estimation results in chart form. Figures will usually include the estimated 1\% VaR (Value-at-Risk) and MES over time for the distribution of signreversed yield changes (i.e. minus the daily yield change measured in basis points). Com- 
parisons are made between SBBS components, individual low-risk and high-risk sovereigns, and a GDP weighted portfolio of euro area sovereigns. For the three-tier tranching structure the VaR and MES analysis was first conducted for the mezzanine as a function of the junior component and then for all other variables as a function of the mezzanine (i.e. for the senior SBBS, individual sovereigns and the EA portfolio). For the two-tier 70:30 tranching case the analysis was conducted with the junior bond placed first in the ordering of the VAR-for-VaR analysis and for conditioning of the MES - implying that the tail risk in the junior tranche is causal.

Figure 1 shows the case of a 70:20:10 tranching structure. This figure displays dot plots of the yield changes of mezzanine (light-blue dots) and junior (light-green dots) tranches of SBBS. We see that the mezzanine observations are distributed with considerably smaller variance than the junior bond observations. Other variables shown in this figure include the $1 \% \mathrm{VaR}$ for the mezzanine and junior tranches (blue and dark-blue lines respectively) and the MES of the mezzanine tranche (dark-red line). The VaRs give a first indication of how volatility is concentrated within the junior tranche. During the most volatile episodes the VaR of the junior tranche exceeds that of the mezzanine tranche by a factor of three. The mezzanine MES measure, which is conditioned on the probability of the junior tranche having a yield change more negative than its $1 \% \mathrm{VaR}$, is often significantly above the mezzanine 1\% VaR and this indicates that tail events in the junior SBBS tend to coincide with less extreme movements in the mezzanine tranche (i.e. holders of the mezzanine benefit from a degree of insurance due to initial losses being accepted by junior bond holders). This is a theme that is repeated in the case of the senior tranche discussed below.

Since the junior SBBS generally has a very negative $1 \%$ VaR (and this is the most extreme SBBS VaR that we examine) it is immediately of interest to consider how this compares with VaRs of some of the high-risk individual sovereigns. Figure 2 shows the 70:20:10 junior SBBS $1 \%$ VaR compared with the $1 \%$ VaRs of each of three individual sovereigns that experienced high volatility during the Sovereign Debt Crisis (Portugal, Ireland and Greece). The Portuguese VaR lies mostly between the junior and mezzanine SBBS VaRs. It is interesting however that even the junior SBBS VaR is not as volatile as the single sovereign VaR and quite often the PT-VaR falls well below the junior SBBS VaR. This reflects the benefits of diversification even for the most junior tranche. For the case of the Irish sovereign VaR, there is clearly a period between the Irish sovereign debt crisis 
(when guarantees given to depositors and senior bank bond holders imposed losses and re-capitalisation costs on the State) and the beginning of 2012 when risks were as great as, and occasionally in excess of, that of the junior SBBS. Otherwise the IE-VaR is practically inseparable from the mezzanine SBBS VaR. The case of the Greek sovereign bond VaR is exceptional. Here it is worth noting that the scale of the vertical axis is roughly twice that of the other two panels. The junior SBBS VaR is almost always higher than the GR-VaR and the latter often plunges several orders of magnitude below the junior VaR. Clearly, the junior VaR benefits from important positive diversification effects.

Figure 3 shows the time profiles of a number of comparisons of risk measures between the German 10-year sovereign bond and the two most senior tranches of the SBBS under a 70:20:10 structure. The mezzanine $1 \% \mathrm{VaR}$ is shown as the bright blue line. The senior SBBS and German 1\% VaRs are shown as bright-green and purple lines respectively. These VaRs are almost indistinguishable from each other implying that the senior bond is just as low-risk as the German bond on the basis of a VaR comparison. The senior SBBS and German bond MES measures are shown as dark-blue and dark-red lines respectively (MES in this case is measured as the expected shortfall conditional on tail events in the mezzanine tranche exceeding the $1 \%$ VaR of that tranche - such losses can only occur after the junior tranche has been fully wiped-out). The MES profiles are very similar, but when volatility is at it highest we notice that the German MES marginally exceeds the senior SBBS MES. This is indicative of slightly lower-risks for holders of the lowest-risk sovereign. This is to be expected since German bonds historically benefited from a flight to safety effect that does not apply so readily to the senior SBBS - the latter suffers losses in the most extreme circumstances by definition whereas the German bond does not necessarily become exposed. Still, there are clearly only slight MES differences between the senior SBBS and the lowest-risk sovereign.

It is worthwhile considering how various single sovereign bonds and a diversified portfolio compare with the risk characteristics of the mezzanine and junior SBBS. Figure 4 shows VaR and MES risk measures for 6 of the relatively low-risk single European sovereigns compared with the VaR for the mezzanine SBBS under the 70:20:10 tranching structure. During volatile periods, these low-risk individual sovereign bonds have 1\% VaRs that stay relatively stable and, in many cases, the whole distribution of returns on the low-risk sovereign shifts upward. Moreover, the MES of these low-risk sovereigns (i.e. the shortfall 
conditional on negative outcomes for the mezzanine SBBS below its 1\% VaR) tends to rise significantly as the crisis intensifies and decline as it passes. This implies that there is a tendency towards positive returns for these lower-risk single-name sovereign bonds when there are extreme losses on the mezzanine SBBS. This is particularly apparent in the case of the German, Finnish and Dutch government bonds.

Figure 5 shows VaR and MES risk measures for the Italian and Spanish sovereign bonds along with the euro area GDP-weighted portfolio. In each case the $1 \% \mathrm{VaR}$ for mezzanine and senior SBBS in the 70:20:10 tranching structure are included. The Italian and Spanish bond VaRs coincide almost exactly with the mezzanine SBBS VaR. The mezzanine tranche is clearly highly comparable with the Italian and Spanish cases. The euro area portfolio has a VaR more in line with the senior SBBS.

The country-specific MES comparisons in Figure 5 suggest that shortfall conditional on mezzanine tail events is of a similar magnitude to the country specific VaRs and (unlike for the low-risk sovereigns) this indicates that these higher-risk sovereigns are not benefiting from virtually any safe-haven status. The cases of Italy and Spain are very clear (i.e. MES and VaR are almost exactly the same as each other in these two cases). In the case of the euro area portfolio, despite being quite similar to other low-risk assets in terms of VaR, the diversified portfolio has MES which is close to its own VaR. This implies that the portfolio provides risk reduction through diversification but does not act as a safe haven or hedge against tail risks.

Turning now to the case where there is a two-tier tranche structure (specifically a 70:30 structure). Figure 6 displays the $1 \%$ VaR and MES results for the senior SBBS along with the 1\% VaR of the junior SBBS. A comparison between the 70:30 case and the 70:20:10 tranching structure can be made by reference to the grey-shaded area which is bordered by MES and VaR of the 70:20:10 tranching structure. It is noticeable that the senior and junior VaRs show some negative correlation during the onset of the Great Financial Crisis but not beyond that. More interestingly, from the beginning of the crisis, the senior SBBS MES rises towards the middle of the yield-change distribution while the junior SBBS VaR becomes extremely negative (in the pre-crisis period the senior SBBS MES stays at the lower fringes of the yield change distribution). This suggests that the senior SBBS is a hedge against the junior SBBS tail risk when tail risk is extremely high. 
The 70:30 case displayed in Figure 6 is not so different from the 70:20:10 situation. This can be verified by noting the small difference between the grey-shaded area and a similar area between the VaR and MES of the 70:30 case. In fact, the 70:30 case also produces similar outcomes to those of the 70:20:10 for all individual sovereigns and the EA portfolio. The same hedging properties tend to be present in the case of the low-risk sovereigns but absent for the higher-risk cases. The euro area portfolio is once again low-risk in terms of its VaR but also does not possess hedging characteristics.9

The expected value of the return on each entity conditional on the return for the junior yield change being in the extreme tail depends critically on the correlation between the returns on individual sovereigns with those of the junior SBBS. When the correlation is close to 1 the MES tends to be close to or below the VaR. If the correlation moves into negative territory the asset pairing involves a hedge relationship and in this case the returns will tend to be observed in opposite sides of their respective distributions. Figure 7 shows this relationship between correlation and MES (where the correlation is for the DE and junior SBBS yield changes while the DE MES is conditioned on the junior SBBS yield change being more negative than the junior SBBS $1 \% \mathrm{VaR}$ ).

\subsection{Return for Risk}

The above analysis considers only comparisons of tail risk exposure and the hedging properties of SBBS assets. We now consider reward for risk. We begin by describing the results of a Sharpe ratio analysis for the holding period returns. As mentioned in the methodology section, this ratio is a little unusual for the case of bonds because coupons sometimes represent a large and changeable component of holding period returns. The results now discussed are based on the case where an equal (and static) coupon and duration is used for the calculations of all holding period returns. The results for the estimated coupons (where coupons are allowed to rise with the yield spread) tend to show relatively larger Sharpe ratios for the riskier bonds/SBBS.

Figure 8 shows the case of the monthly holding period Sharpe ratios for the senior, mezzanine and junior tranches of the SBBS combined with the Sharpe ratios for the monthly holdings of German sovereign bonds (these are all for the 10 year maturity and for the

\footnotetext{
${ }^{9}$ The additional results for the 70:30 case are available from the authors.
} 
70:20:10 tranching structure). In each case we allow the coupon to have an upper and lower bound of one standard deviation around the chosen coupon rate based on the standard error of the intercept coefficient in the regression of the coupon spread on yield spread as discussed in the methodology section. This reveals that Sharpe ratios are generally close together. All Sharpe ratios are low and declining during the Great Financial Crisis until 2010. The financial crisis began to affect peripheral sovereigns during 2010. This seems to coincide with an increase in the Sharpe ratios for the mezzanine, senior and German sovereigns (perhaps reflecting safe haven flows). The junior SBBS turns around later and it is plausible that the ECB's non-standard monetary policy measures were responsible for reducing the risks associated with holding the higher-risk sovereigns and therefore the junior SBBS. Sharpe ratios tend to rise towards early-2012 (with the junior SBBS peaking far above the others at a value near 9) and then all but the junior SBBS tend to stay around a value of 4 for the remainder of the sample while the Sharpe ratio of the junior SBBS declines to zero or below for the end of the sample.

Figure 9 is the same as the previous figure except that the German Sharpe ratio is replaced by the Sharpe for the euro area portfolio (EA Sharpe). Firstly, the EA Sharpe is very similar to the German case. The EA portfolio gives slightly more reward for risk than the senior and mezzanine SBBS during the crisis periods but otherwise it is very similar to these. Figure 10 shows the SBBS Sharpe ratios against the background of the spread between the lowest and highest individual sovereign Sharpe ratios over time (the purple shaded area). This indicates that the SBBS Sharpe ratios (excluding the junior) are generally contained within the range covered by individual sovereigns. On this basis it appears that the SBBS provide as good (if not better) holding period reward for risk to that of the individual sovereigns.

We now examine the compensation for risk where risk is measured either as GJRGARCH conditional volatility or as VAR-for-VaR (these are therefore variations of the concept underlying the simple Sharpe ratio). ${ }^{10}$ Figure 11 shows the dynamic relative reward

\footnotetext{
${ }^{10}$ This analysis is conducted without considering the fact that coupons could be distributed differently than is presumed under the estimation of SBBS historical yields. Since the senior SBBS is as low-risk as the German bund it is likely that it would be rewarded with a coupon no greater than the bund. This is less than what is paid on the pool of low-risk sovereigns and the prospect of redistributing such extra coupons to the junior SBBS arises. Such a redistribution would change the warranted yield-to-maturity of the junior tranche relative to what we have assumed in our SBBS yield estimations.
} 
for GJR-GARCH conditional volatility of individual sovereigns, the euro area portfolio and senior, mezzanine and junior SBBS. The top panel considers the comparison for the group of low-risk sovereigns while the bottom panel pertains to the relatively more risky sovereigns. The sample average comparison is shown in Figure 12 .

It is clear from the time-varying Sharpe ratios in the top panel of Figure 11 that the senior SBBS is rewarded in a very similar manner to the German bond. Both seem underrewarded when compared with other low-risk sovereigns but this reflects the fact that they have substantial flight-to-safety price premiums. The black dotted line represents the Sharpe ratio for the senior SBBS in the top panel. This almost always lies directly over the German reading (shown in purple). There is some evidence of a difference between the German and senior SBBS during the pre-crisis period (this was a period when German bonds attracted a slightly higher return for yield - perhaps due to the fiscal situation in Germany driving bond prices down slightly with little change in volatility). Overall however, there is very little difference between the senior SBBS and the German bond in terms of their yield-to-maturity relative to GJR-GARCH volatility. This confirms the ranking of the senior bond in our earlier analysis based purely on risk. The Sharpe ratio on average in Figure 12 confirms the approximate equality between German and senior SBBS. We also see that the mezzanine has a similar reward ratio to that of the French bond. It is notable that the GDP-weighted euro area portfolio frequently has the highest yield relative to volatility. This reflects the strong diversification effects available (with many low and sometimes negative pairwise correlations).

The time varying Sharpe ratios in the bottom panel of Figures 11 and 12 reveal that the junior SBBS is generally not well compensated for its volatility. This under-performance is more prominent in the pre-crisis period. During the crisis and post-crisis period there is regularly a relatively high ranking of the junior SBBS in terms of reward for risk. As mentioned above, there is a possibility that the junior bonds may be subject to receipt of extra coupons relative to what is assumed in the Monte Carlo analysis. On this basis it seems that junior tranches could be made more attractive to investors. While the junior SBBS does not appear to be well compensated it is clear that the mezzanine is very much in line with the relatively high-risk sovereigns such as Spain, Italy, Ireland and Portugal.

In Figures 13 and 14 the dynamic and average yield for absolute Value-at-Risk earned 
by individual sovereigns, the euro area portfolio and the senior, mezzanine and junior SBBS are shown (the average in Figure 14 is for the whole sample from January 2002 to October 2016). Once again, the top panel considers the comparison between a euro area portfolio, senior and mezzanine SBBS and the group of lower-risk individual sovereigns. The comparison in the bottom panel pertains to the riskier sovereigns (the junior SBBS is included). It turns out that there are very few differences between a VaR based risk-return assessment and one based on conditional volatility - except for the case of the junior SBBS where the reward for risk is no longer such an outlier. The euro area portfolio performs best overall (but recall that this portfolio has little of the hedging properties possessed by the German or senior bonds). The senior bond has a reward for risk which is very similar to that of the German bond. The bottom panel of Figure 14 reveals that the junior SBBS provides a reward for risk (using Value-at-Risk) than borders the lowest performers (albeit not as outlying). Overall, the SBBS are not excessively out-of-line with other similarly risky single sovereigns.

\section{Conclusion}

The analysis above examines the ex ante tail-risk characteristics of sovereign bond-backed securities as proposed by Brunnermeier et al (2011, 2016, 2017). The results of this analysis largely confirm the simulation-based results of Brunnermeier et al using correlated probabilities of defaults and expected loss given default calibrated on historical data. The original simulations found that senior SBBS would be exposed to smaller amounts of risk than even the lowest-risk existing euro area sovereign bond and that junior SBBS would surpass most euro area periphery sovereigns in their pricing. Using Value-at-Risk and Marginal Expected Shortfall measures we have found that senior SBBS are almost as low-risk as the lowest-risk euro area sovereign (including as a hedge against the extreme risk of many defaults). The mezzanine SBBS is very similar to Spanish and Italian bonds using all risk measures. The junior SBBS under a 70:20:10 tranching structure is not as high-risk as the highest-risk single sovereign but is usually more exposed to market-based losses than sovereigns with intermediate levels of risk exposures. On this basis, the junior bonds may attract investor interest when one considers their likely higher liquidity than existing single high-risk sovereigns. 
We found that the senior SBBS has a yield-to-maturity relative to Value-at-Risk that is similar to that of the German bund. The junior bond frequently outperforms in terms of the dynamic Sharpe ratio. In the pre-crisis period and at the end of the sample it under-performs. However, since junior bonds may benefit from higher coupons (as a net benefit from the securitisation), and are likely to be more liquid than comparable individual sovereigns, it should be possible to enhance the junior components of SBBS to make them attractive to investors.

While the VAR-for-VaR approach is flexible, in that it allows for cross-effects, it does not allow for changing parameters in the VAR. Tail risk spillovers may primarily be a feature of crisis circumstances so allowing for parameters to switch in such circumstances may materially affect the findings above. The MES analysis reminds us that the correlation between low- and high-risk assets matters a lot for the perceived (and actual) risk exposure in crisis situations. Some individual sovereigns have very attractive hedging properties (i.e. high MES) and, while this feature is passed on to the senior SBBS, it may be counteracted by actual exposure to losses in the rare circumstance of a very large number of defaults. Our simulations have accounted for these circumstances by assuming a very high correlation for defaults in each period. While we have calibrated the yield estimation process to guard against a safe-haven bias we have not tried to represent the benefits that securitisation might bring in terms of reducing risks due the breaking of a bank-sovereign diabolic-loop. In this respect, our findings are more likely to be an understatement of the benefits of securitisation. 


\section{Bibliography}

Acharya, V., R. Engle, and M. Richardson (2012). Capital shortfall: A new approach to ranking and regulating systemic risks. American Economic Review 102 (3), 59-64.

Adrian, Tobias, and Markus K Brunnermeier (2016) Co-VaR. American Economic Review 106(7):1705-1741.

Brownlees, C. T. and R. Engle (2012). "Volatility, correlation and tails for systemic risk measurement". Working Paper. SSRN Paper Download

Brownlees, C. and R. F. Engle (2017). SRISK: A Conditional Capital Shortfall measure of systemic risk. Review of Financial Studies 30(1), 48-79.

Brunnermeier, M, L Garicano, P Lane, M Pagano, R Reis, T Santos, D Thesmar, S Van Nieuwerburgh, and D Vayanos (2011), "European Safe Bonds", The Euronomics Group, Summary available at VoxEU.org.

Brunnermeier, M. K., L. Garicano, P. Lane, M. Pagano, R. Reis, T. Santos, D. Thesmar, S. Van Nieuwerburgh, and D. Vayanos (2016, May). The sovereign-bank diabolic loop and ESBies. American Economic Review Papers and Proceedings 106 (5), 508-512.

Brunnermeier, M. K., S. Langfield, M. Pagano, R. Reis, S. van Nieuwerburgh, and D. Vayanos (2017). ESBies: Safety in the tranches. Economic Policy 32 (90), 175-219.

Cecchetti, S. and A. Di Cesare (2012) The Mathematics of the Relationship between the Default Risk and Yield-to-Maturity of Coupon Bonds. Working Paper 1203.6723, arXiv.org. Engle, Robert F. and Simone Manganelli (2004) CAViaR: Conditional Autoregressive Value at Risk by Regression Quantiles. Journal of Business 83 Economic Statistics, 22:(4) 367381.

ESRB High-Level Task Force on Safe Assets (2018). Sovereign bond-backed securities: A feasibility study. European Systemic Risk Board.

Glosten, L. R., R. Jagannathan, and D. E. Runkle (1993). On the relation between the expected value and the volatility of the nominal excess return on stocks. Journal of Finance, 48(5), 1779-1801.

Koenker, R. and G. Basset (1978) Regression Quantiles. Econometrica, 46(1):33-50.

Manganelli, Simone, Halbert White and Tae-Hwan Kim (2015) VAR-for-VaR: Measur- 
ing Tail Dependence Using Multivariate Regression Quantiles. Journal of Econometrics, 187:169-188.

Scaillet, O. (2005) Nonparametric Estimation of Conditional Expected Shortfall. Insurance and Risk Journal, 74:639-660.

Silverman, B. W. (1986) Density Estimation for Statistics and Data Analysis. Chapman and Hall, London.

Sharpe, W. F. (1966) Mutual Fund Performance. Journal of Business, 39:119-138.

Sharpe, W. F. (1994) The Sharpe Ratio. Journal of Portfolio Management, 21:49-58.

Shirvani, H. and B. Wilbratte (2005) Duration and Bond Price Volatility: Some Further Results. Journal of Economics \& Finance Education, 4(1):1-6. 


\section{$6 \quad$ Figures}

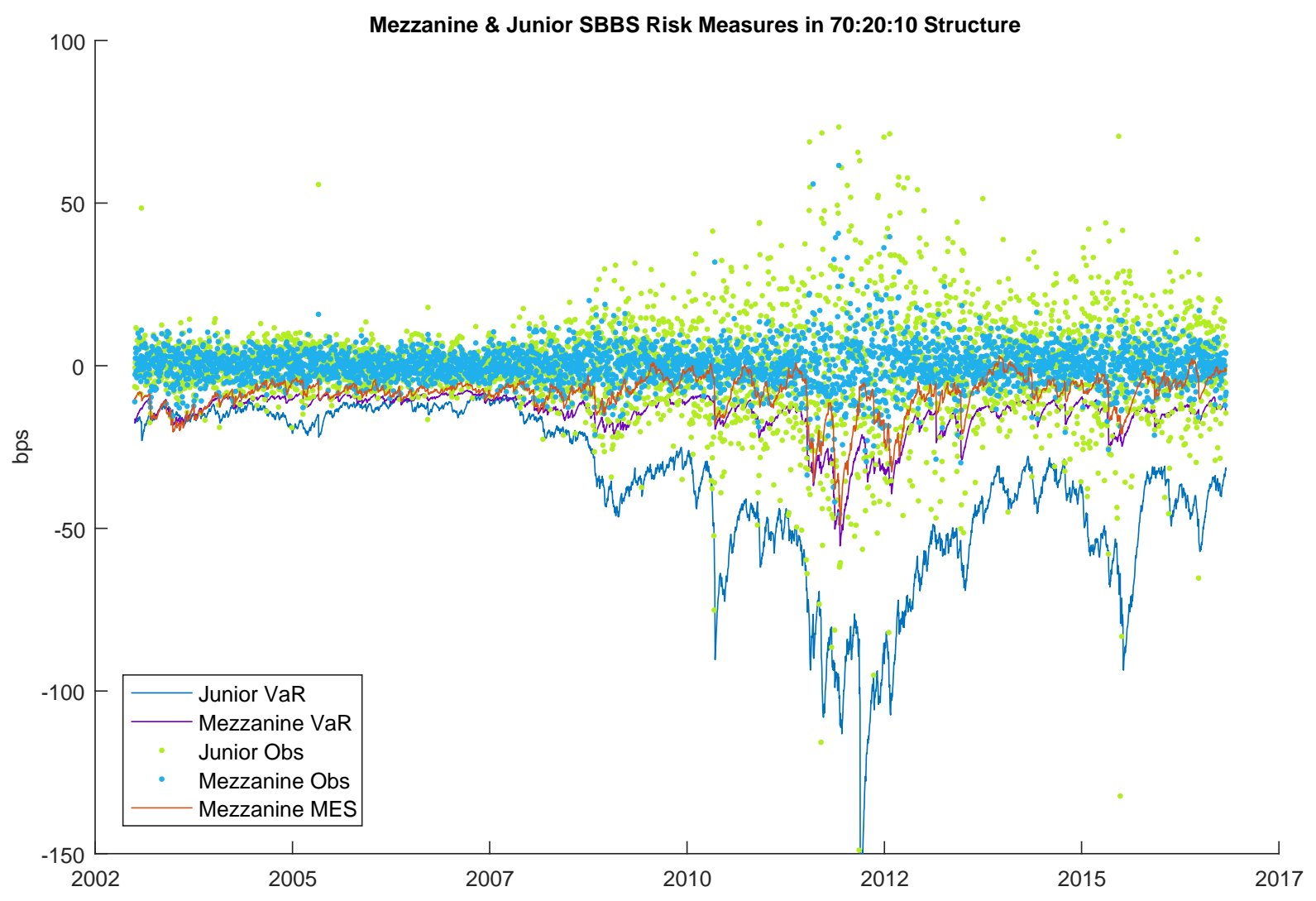

Figure 1: For the case of a 70:20:10 tranching structure this figure displays dot plots of the observed changes in yields in basis points on mezzanine (Light-Blue dots) and junior (Light-Green dots) tranches of SBBS along with 1\% VaR and MES measures of risk exposures. The blue and dark-blue lines represent the $1 \%$ VaRs for the junior and mezzanine SBBS respectively while the MES for the case of the mezzanine tranche, conditional on the junior tranche having a yield change more negative than its VaR, is displayed as a dark-red line. 

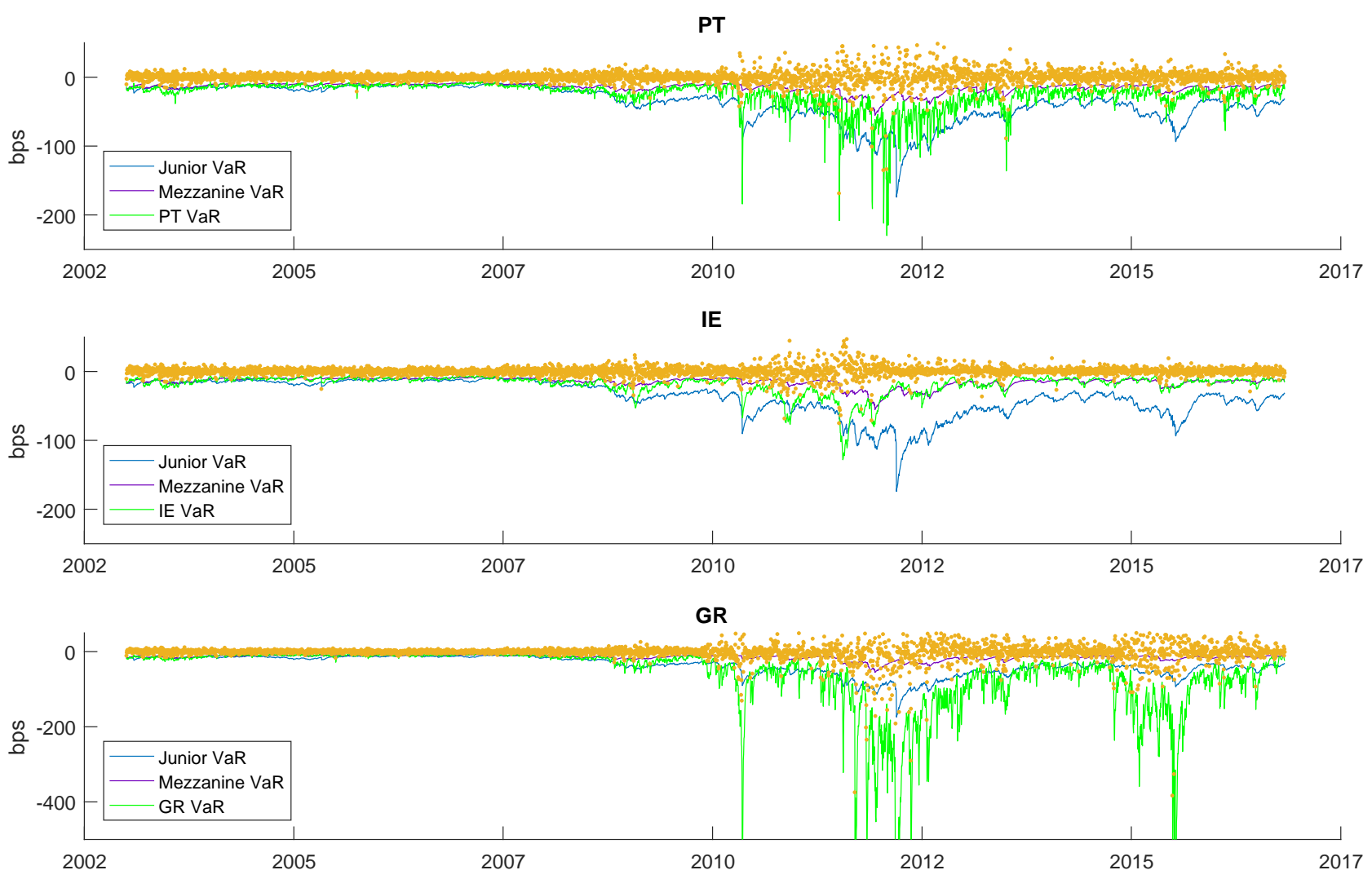

Figure 2: This figure shows the 70:20:10 junior SBBS 1\%VaR compared with the 1\%VaRs of each of three individual high-risk sovereigns (Portugal, Ireland and Greece). 


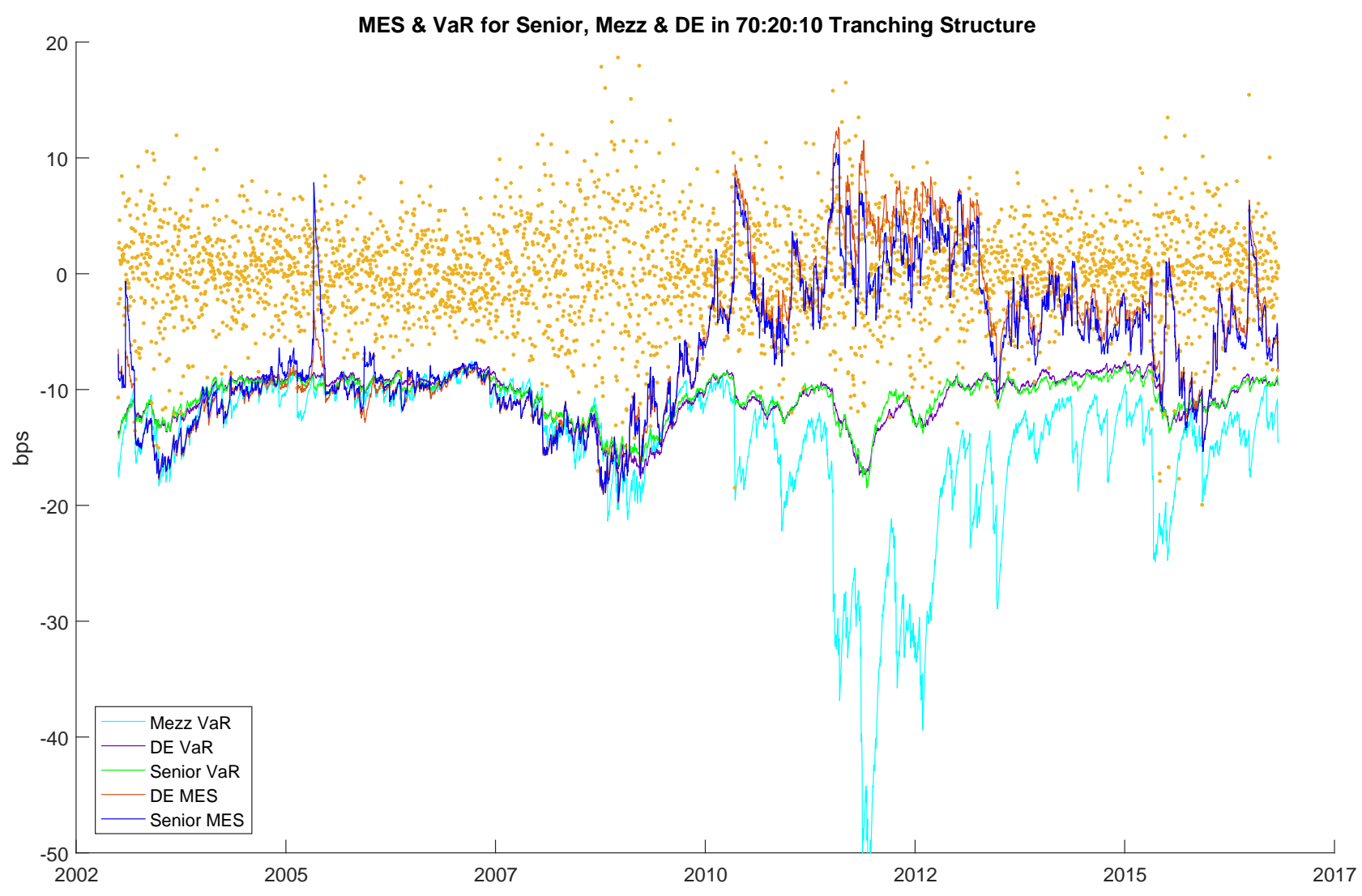

Figure 3: This figure shows the time profiles of comparisons of risk measures (in basis points) of the German 10-year sovereign bond and the two most senior tranches of the SBBS under a 70:20:10 structure. The mezzanine 1\% VaR is shown as the bright-blue line. The senior SBBS and German $1 \%$ VaRs are shown as bright-green and purple lines respectively. The senior SBBS and German bond MES risk exposure measures are shown as dark-blue and dark-red lines respectively (MES in this case is measured as the expected shortfall conditional on tail events in the mezzanine tranche exceeding the $1 \% \mathrm{VaR}$ of that tranche - such extreme mezzanine losses can only occur after junior bond holders have been wiped out). 

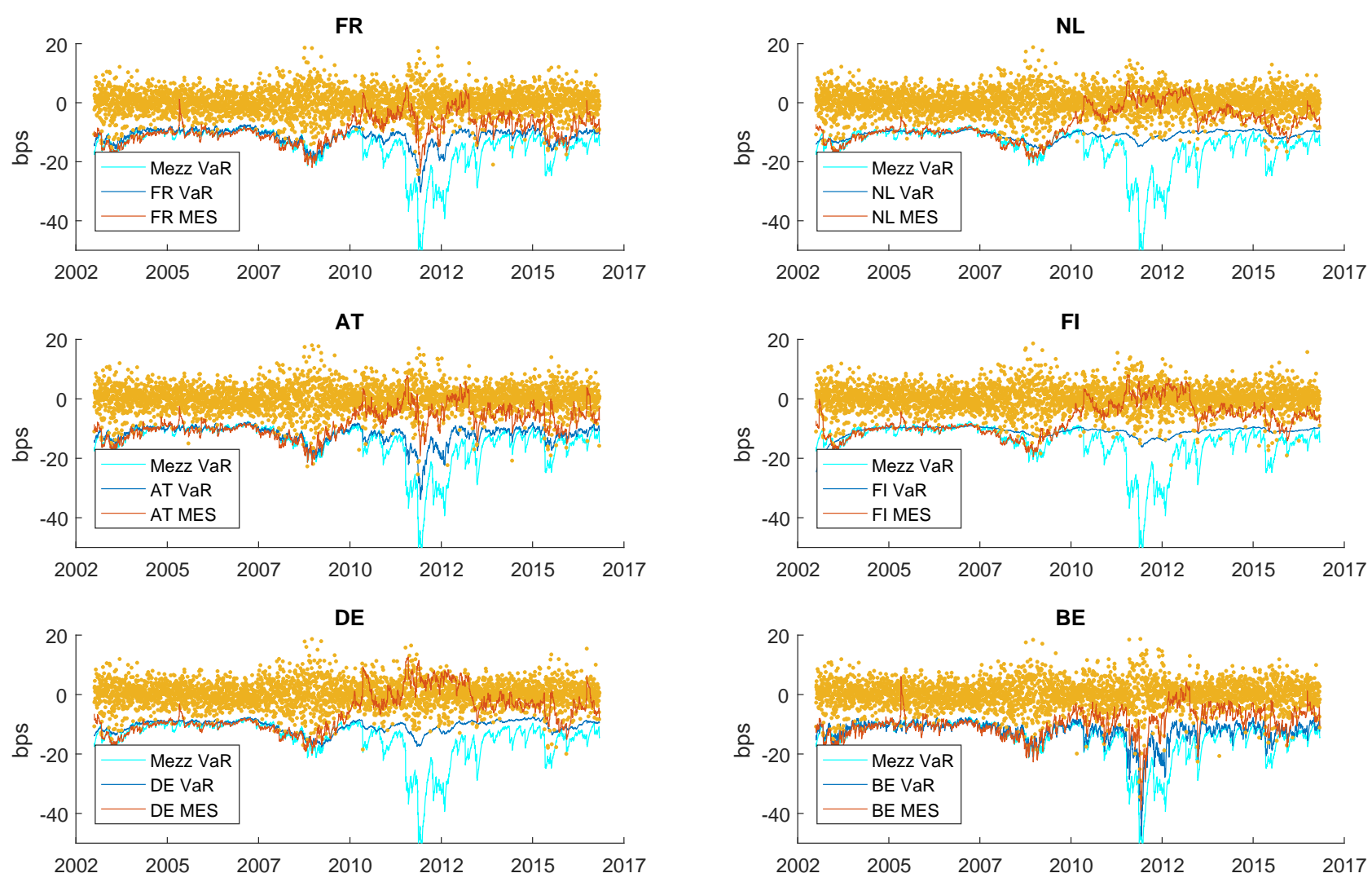

Figure 4: This figure shows VaR and MES risk measures for 6 of the relatively low-risk single European sovereigns compared with the VaR for the mezzanine SBBS under the 70:20:10 tranching structure. 

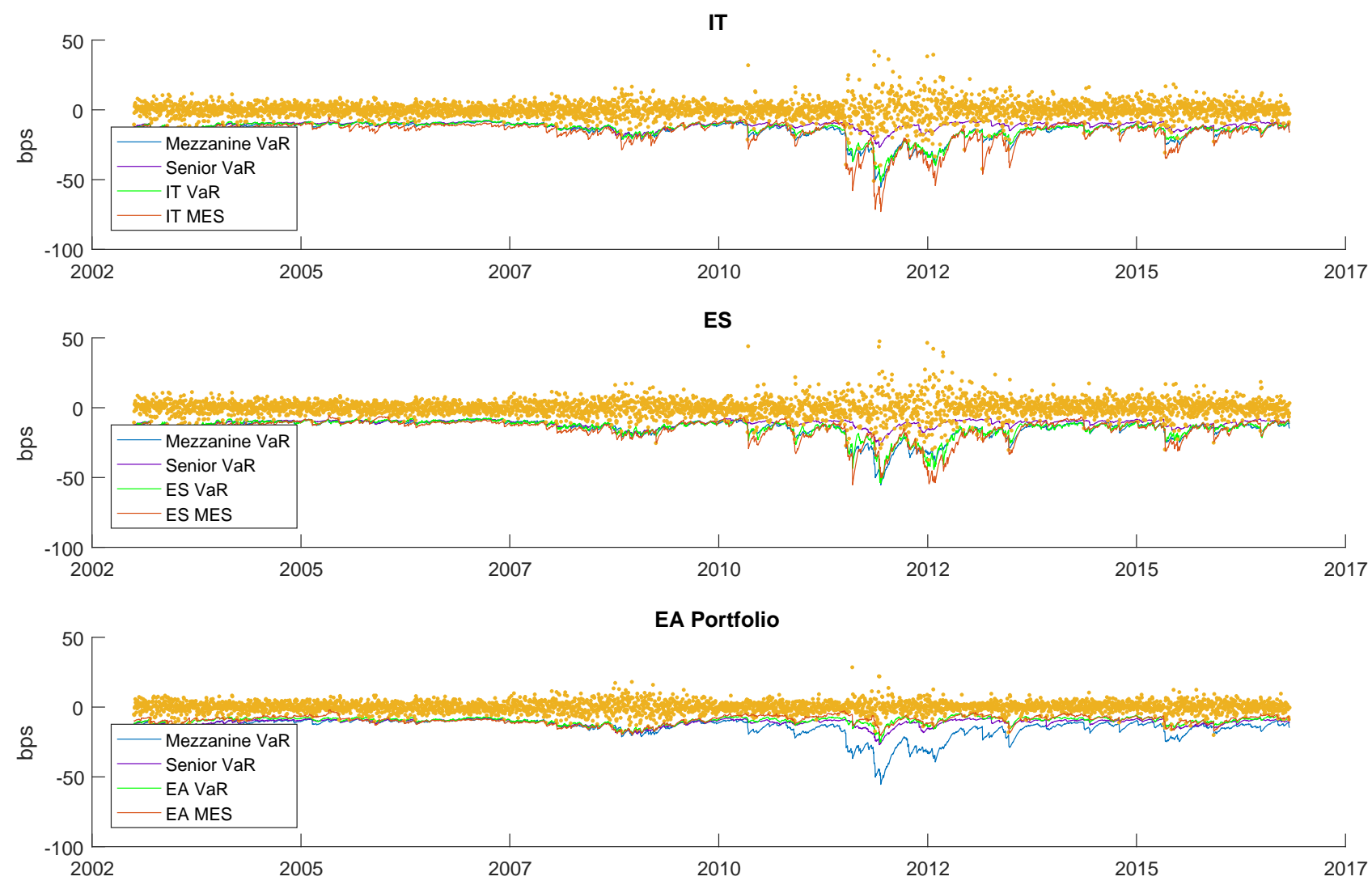

Figure 5: This figure shows VaR and MES risk measures for Italian and Spanish sovereign bonds along with those for a euro area GDP-weighted portfolio. These are compared with the $1 \%$ VaR of senior and mezzanine SBBS under the 70:20:10 tranching structure. 


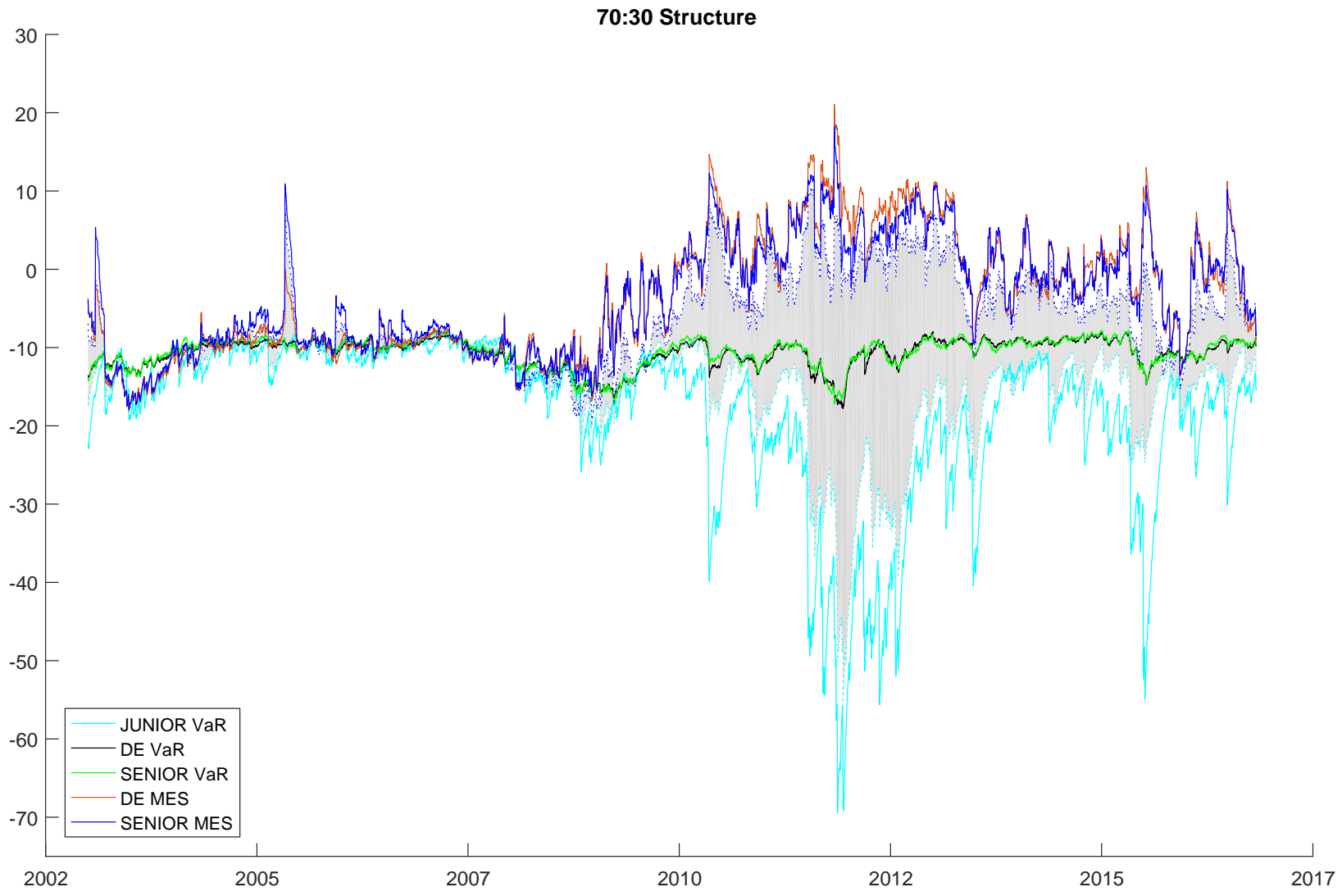

Figure 6: This figure displays the 1\% VaR and MES for the senior SBBS with 10 years to maturity where the single tranche level is $30 \%$. The $1 \%$ VaR for the junior SBBS is included. A comparison between the 70:30 case and the 70:20:10 tranching structure can be made by reference to the greyshaded area which is bordered by MES and VaR of the 70:20:10 tranching structure. 


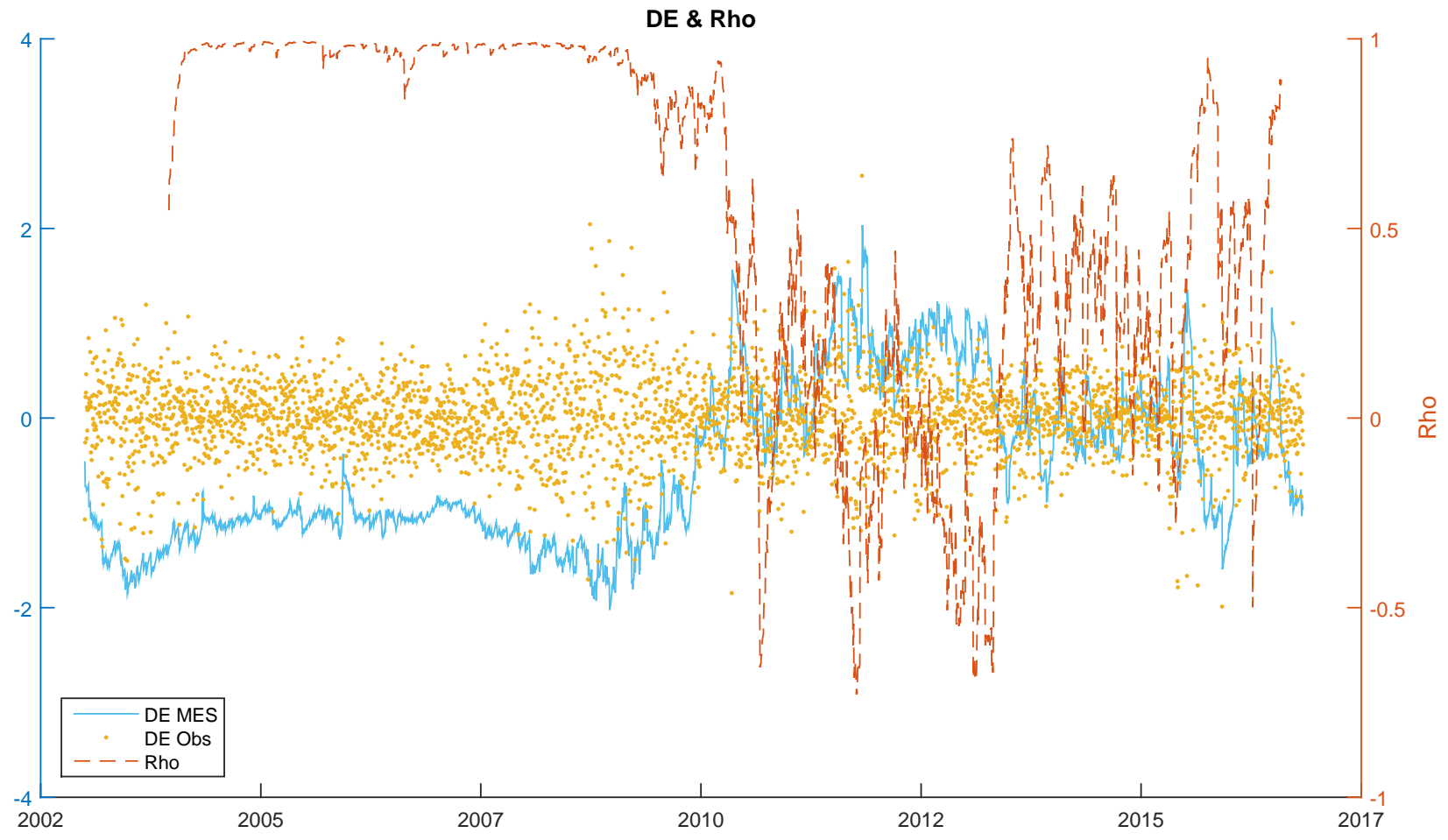

Figure 7: This figure displays the 1\% VaR and MES for 10 Year German Sovereign Bond along with the coefficient of correlation between yield changes of the Bund and junior SBBS (derived from DCC Garch analysis). The correlation coefficient changes to negative during the crisis and this affects the estimate of the MES making it more positive. 


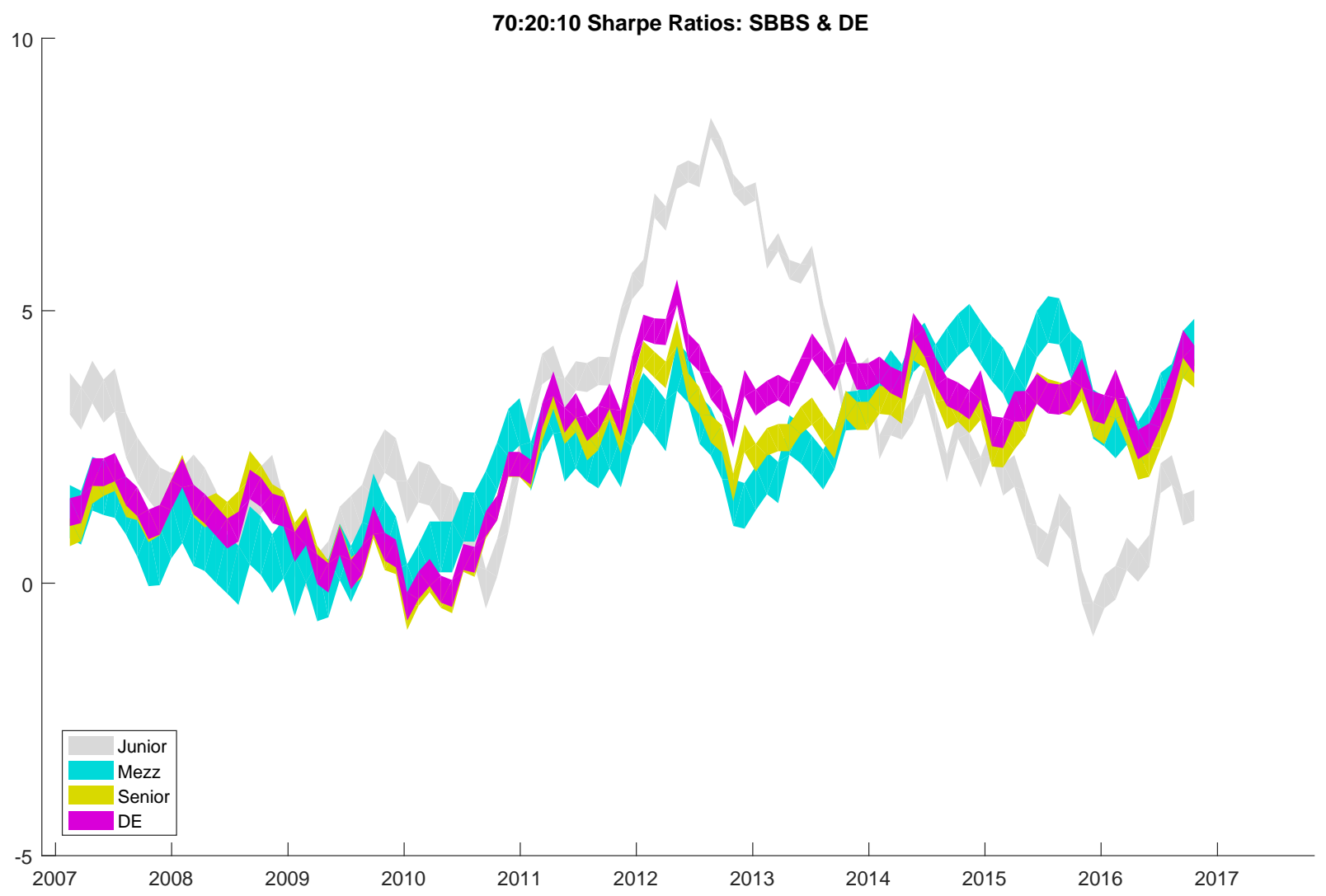

Figure 8: This figure displays the dynamic Sharpe ratio associated with monthly holding of senior, mezzanine and junior tranches of the SBBS and of German sovereign bonds (these are all for the 10 year maturity and for the 70:20:10 tranching structure). In each case we allow the coupon to have an upper and lower bound of one standard deviation around the chosen rate based on the standard error of the intercept coefficient in the regression of the coupon spread on yield spread as discussed in the methodology section. 


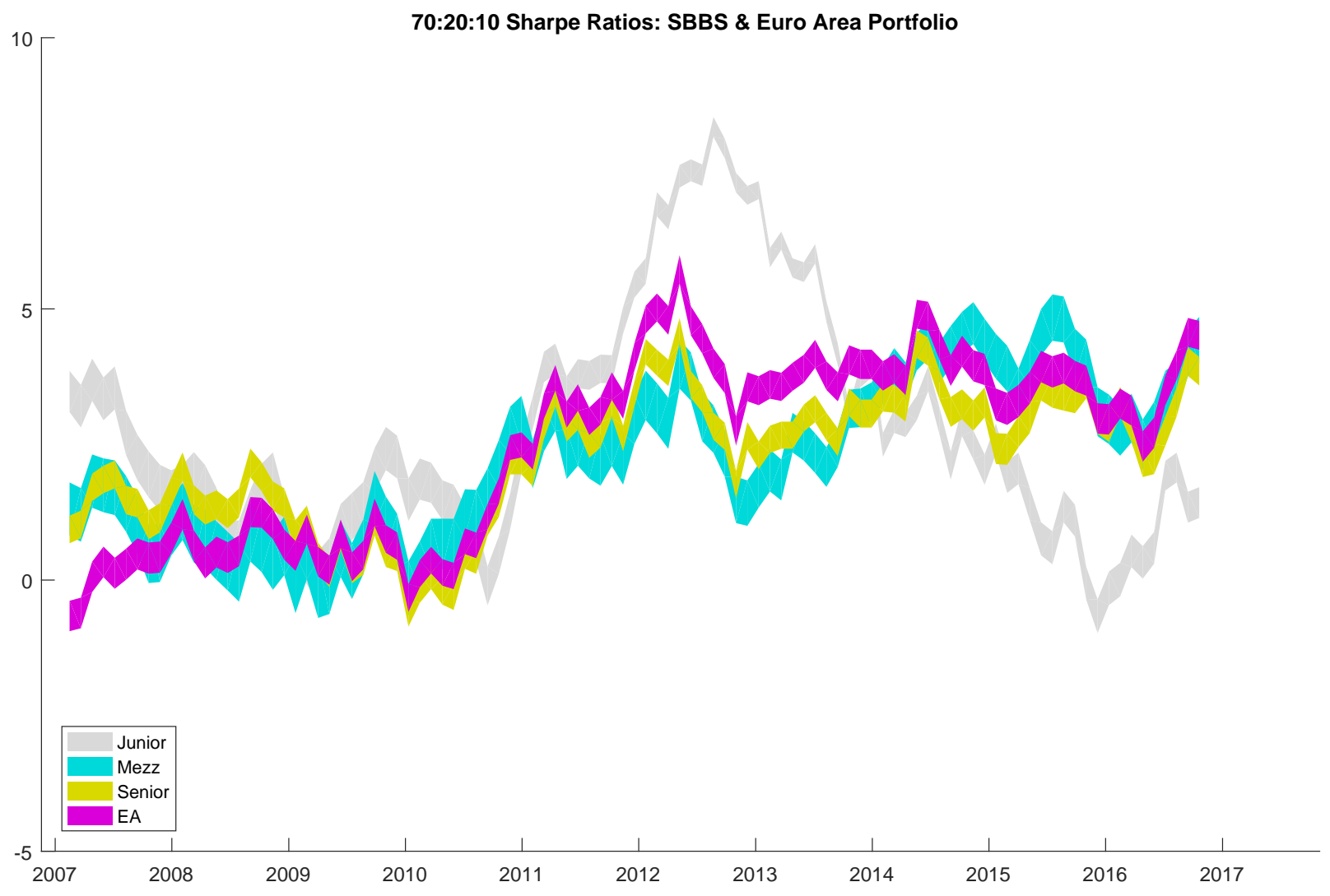

Figure 9: This figure displays the dynamic Sharpe ratio associated with monthly holding of senior, mezzanine and junior tranches of the SBBS and of the GDP weighted euro area portfolio of sovereign bonds (these are all for the 10 year maturity and for the 70:20:10 tranching structure). In each case we allow the coupon to have an upper and lower bound of one standard deviation around the chosen rate based on the standard error of the intercept coefficient in the regression of the coupon spread on yield spread as discussed in the methodology section. 


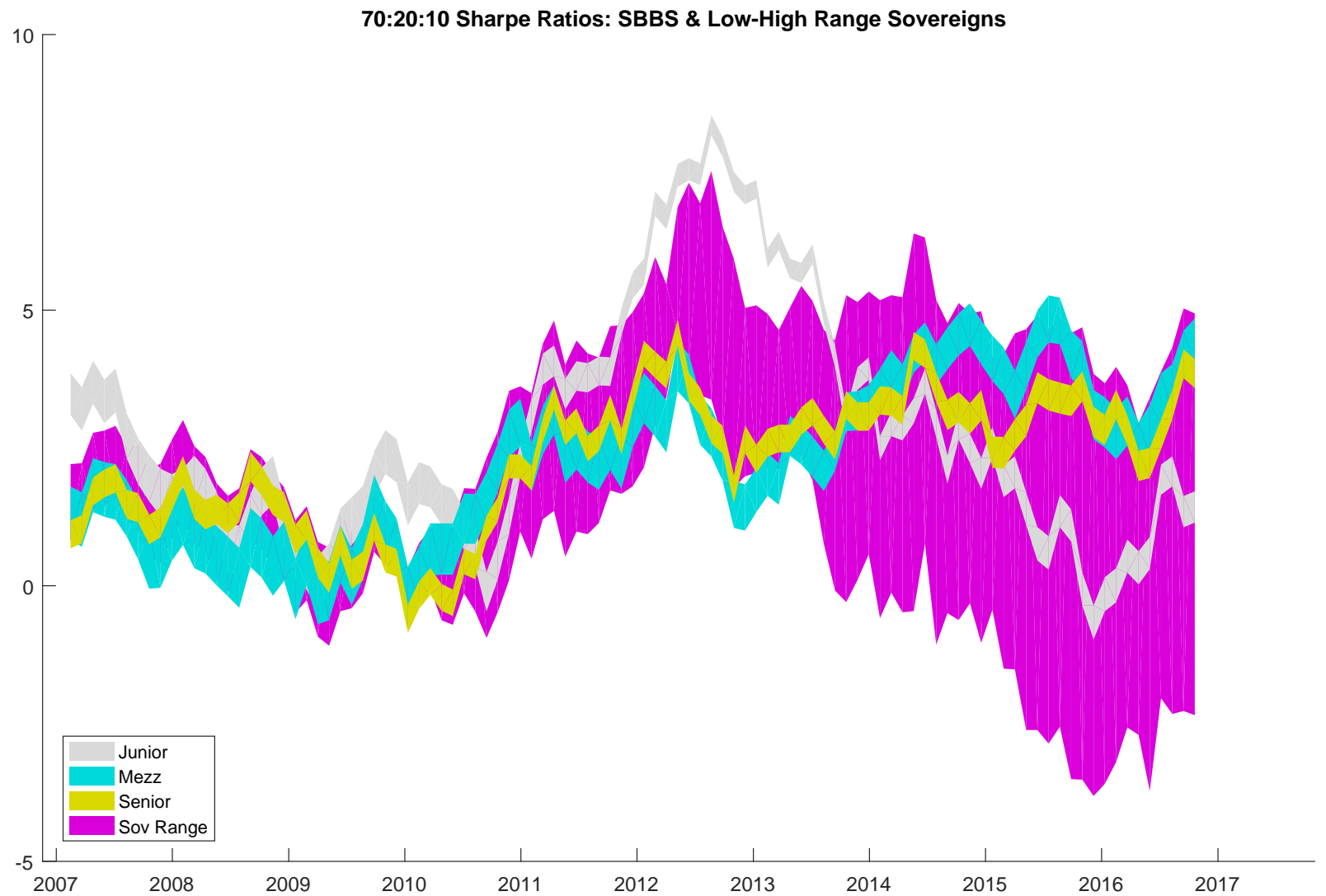

Figure 10: This figure displays the dynamic Sharpe ratio associated with monthly holding of senior, mezzanine and junior tranches of the SBBS (these are all for the 10 year maturity and for the 70:20:10 tranching structure). The purple shaded area shows the area between the lower and upper bounds of observed Sharpe ratios across the euro area individual sovereigns. In each case we allow the coupon to have an upper and lower bound of one standard deviation around the chosen rate based on the standard error of the intercept coefficient in the regression of the coupon spread on yield spread as discussed in the methodology section. 

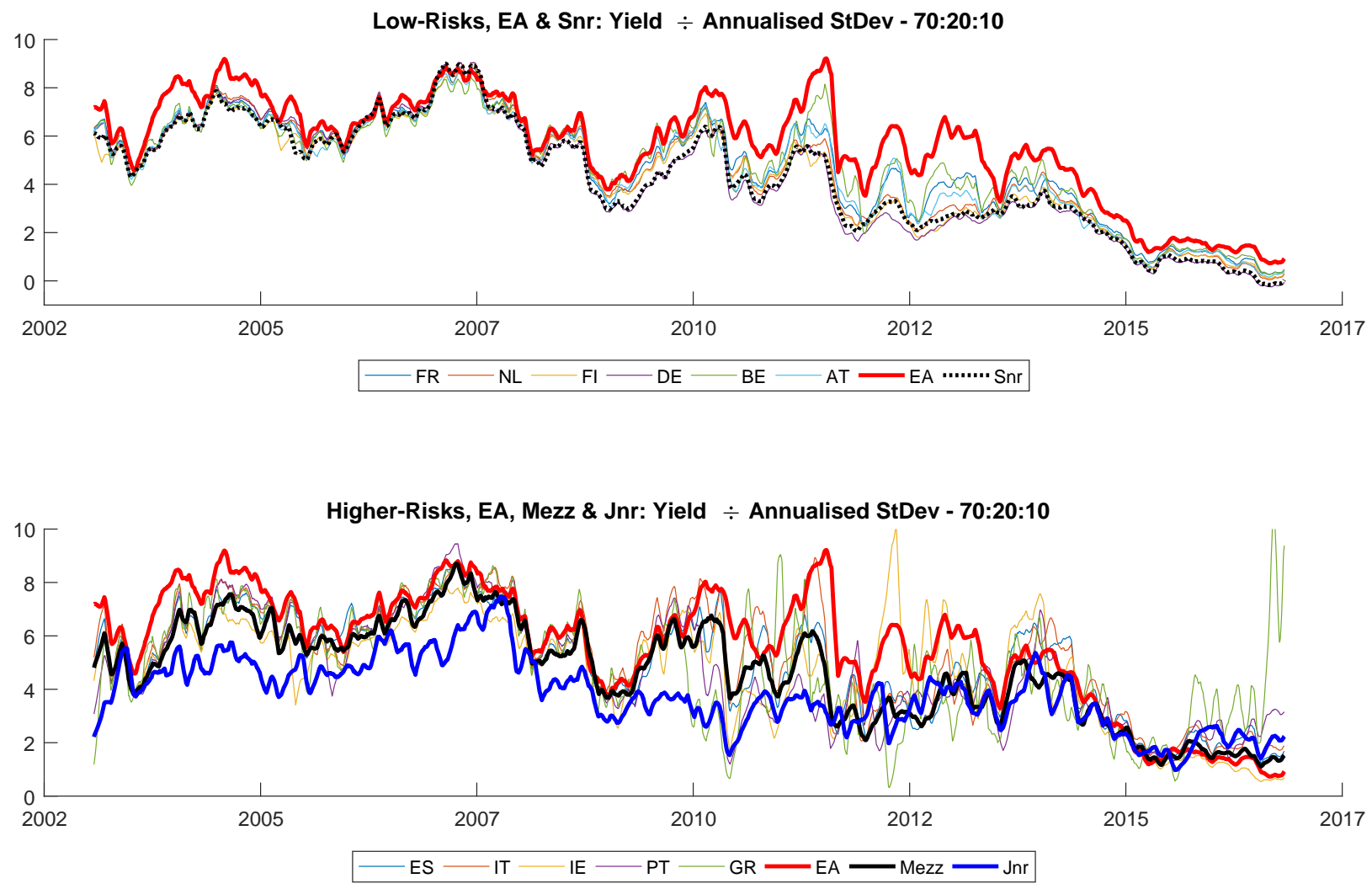

Figure 11: Dynamic Quasi-Sharpe Ratio: Yield for Annualised Risk. In this case risk is measured as GJR-GARCH Conditional Volatility. 

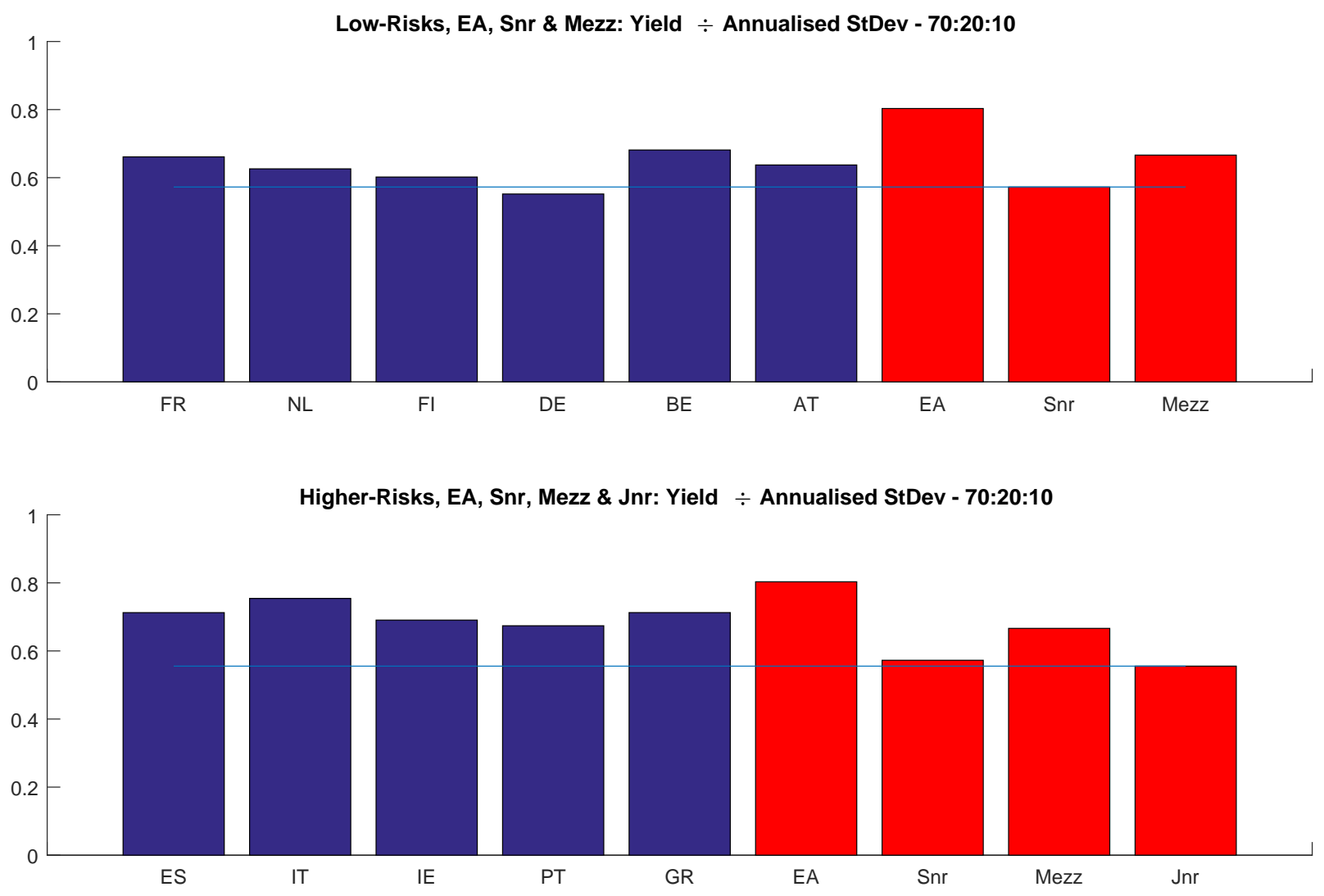

Figure 12: Average Quasi-Sharpe Ratio: Yield for Annualised Risk. In this case risk is measured as the average of the GJR-GARCH Conditional Volatility across the sample. 

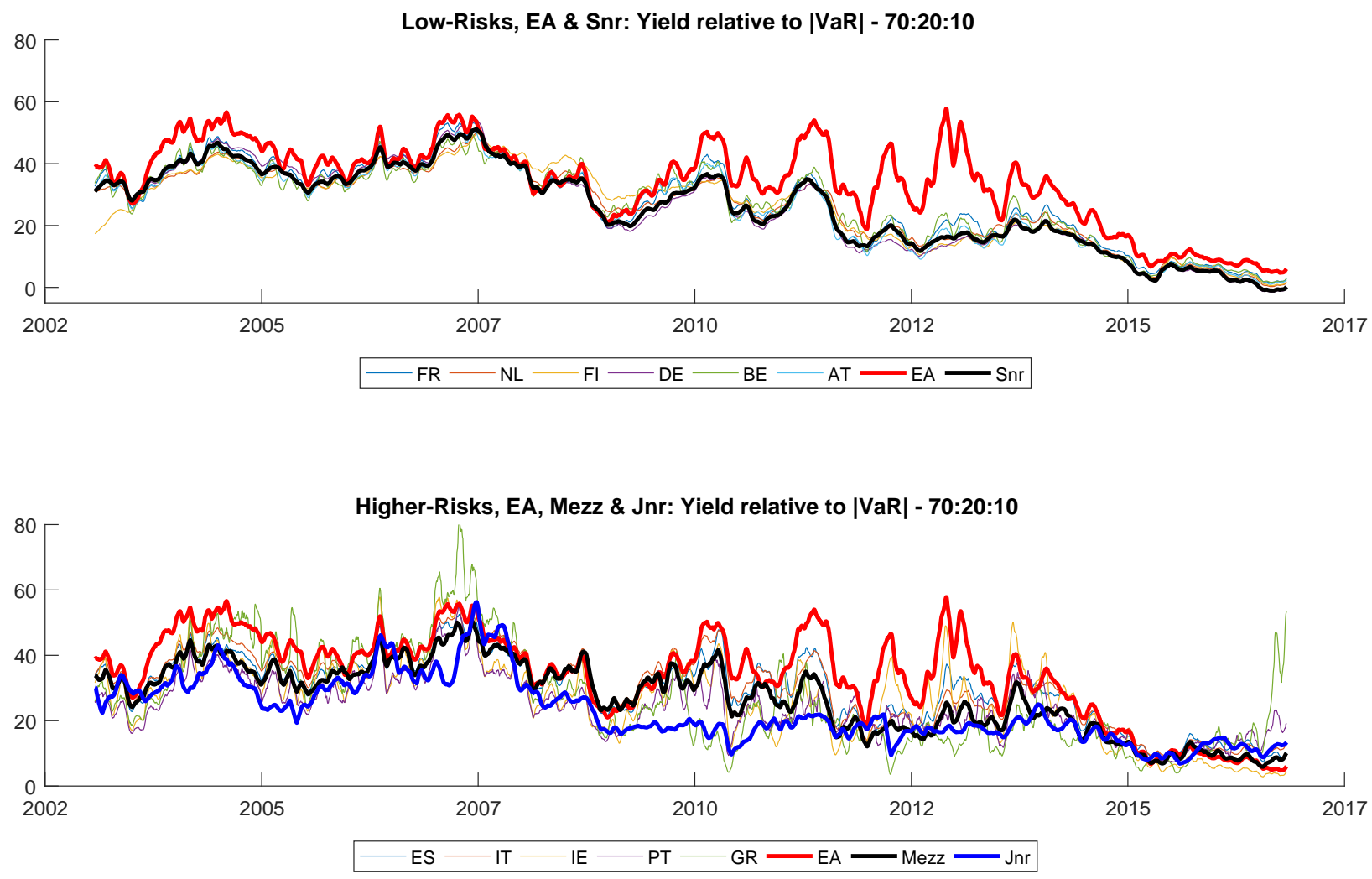

Figure 13: Dynamic Yield for Tail Risk: $\mathrm{YTM}_{t} \div \mathrm{Abs}(\mathrm{VaR})_{t}$. The graphed observations have been smoothed by taking the centered moving average over a rolling 20 observations. 

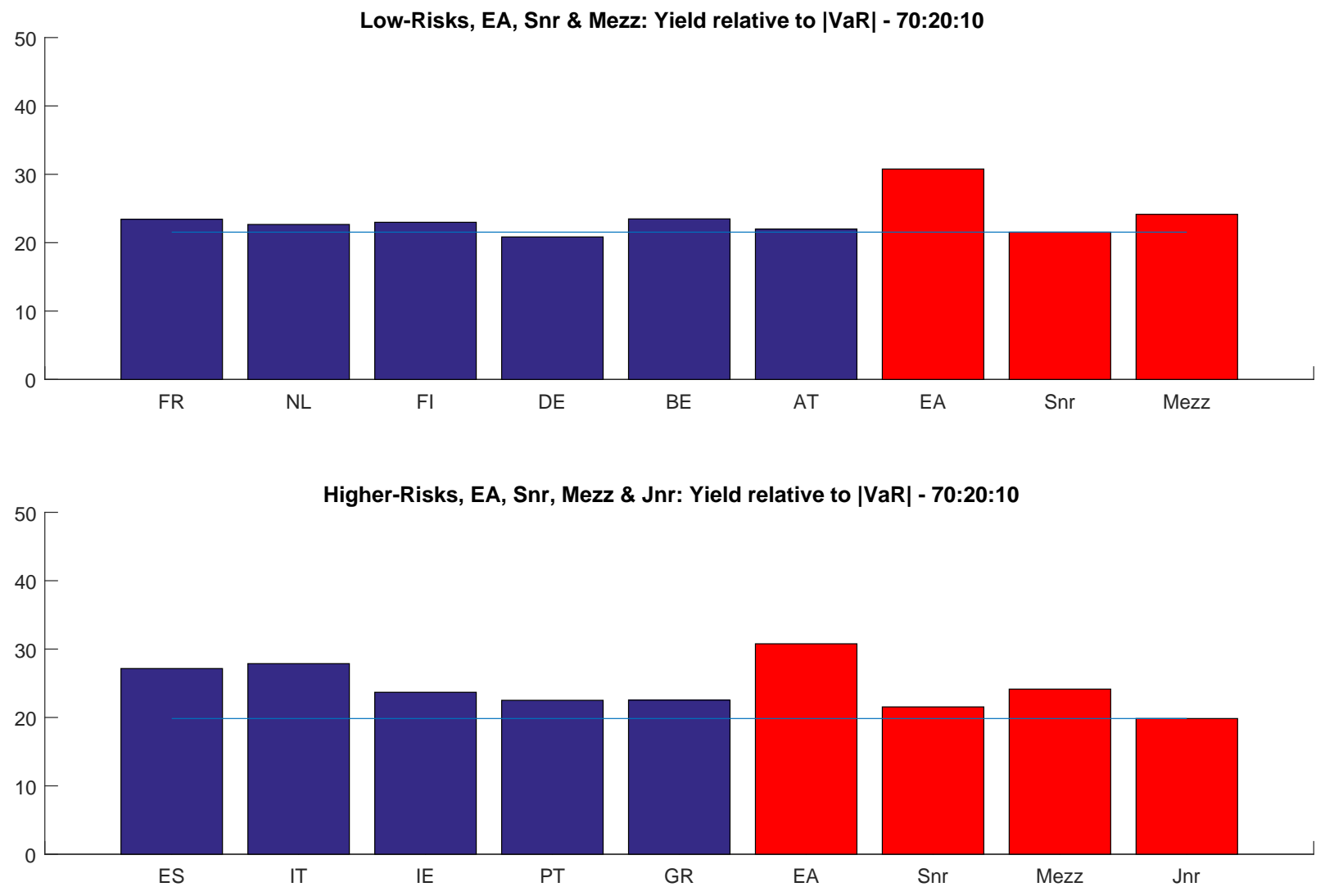

Figure 14: Average Yield for Tail Risk: Average $\left(\mathrm{YTM}_{t} \div \operatorname{Abs}(\mathrm{VaR})_{t}\right)$. 